Tradução: Lucas Eskinazi e Nina Guedes

palavras-chave: arte contemporânea; Gilles Deleuze; Peter Watkins

keywords: contemporary art; Gilles Deleuze; Peter Watkins

* Brown University em Rhode Island.

\section{Power of the false.}

Neste texto em forma de diário, o artista Eric Baudelaire imagina uma exposição cuja premissa seria questionar, através de trabalhos artísticos, as margens entre documento e ficção. Citando realizadores iconoclastas e iconofílicos, uma terceira via é elaborada a partir dos filmes de Peter Watkins para borrar tais fronteiras, a fim de repensar a História e suas representações. Também em sua escrita Baudelaire transita do coloquial à crítica de arte. Em viagens, o artista toma nota de acontecimentos casuais, em meio às quais relembra catástrofes como a Shoah e as bombas atômicas lançadas em Hiroshima e Nagasaki. O título, "potências do falso", faz referência ao conceito de Gilles Deleuze, relevante ao se pensar a produção e circulação das imagens no contemporâneo.

In this text, that takes the form of a journal, the artist Eric Baudelaire pictures an exhibition that would interrogate, through the articulation of artworks, the limits between document and fiction. Commenting iconoclasts and iconophiles filmmakers, Baudelaire brings a third way of relation with images, which is developed by Peter Watkins' border-blurring movies, in order to rethink History and its representations. The author transits, in his writing, through art criticism and a colloquial speech as well. During his trips, Baudelaire takes notes of casual events recalling catastrophes such as the Shoah and Hiroshima and Nagasaki's atomic bombs. The title, "power of the false", refers to Gille Deleuze's concept, relevant to the questioning of image production and circulation nowadays. 
Uma garota desacordada nos braços da mãe, papéis carcomidos, soldados prontos para atacar. À esquerda, uma repórter com sua equipe de filmagem recém-chegada ao local de mais um palco das intermináveis guerras no Oriente Médio. The dreadful details é um díptico fotográfico apresentado por Eric Baudelaire no festival de fotojornalismo Visa pour l'image, em 2006, na França. Comissionado a realizar um trabalho artístico sobre conflitos contemporâneos, esperava-se de Baudelaire uma fotografia de paisagens desoladas, conta o artista. Ao invés disso, Baudelaire vai a outro epicentro da guerra, o das imagens: o díptico apresentado no festival é uma cena feita em um pequeno vilarejo no Novo México, Estados Unidos, que vinha há anos servindo como cenário para as diversas guerras narradas por Hollywood. A aparente ficção das imagens também pode ser vista como documento quando se pensa na força das realidades produzidas por este cinema.

Na ocasião do festival, Elliott Erwitt, fotógrafo renomado, explicitou seu desagrado frente à presença de The dreadful details, dizendo que deveriam escrever FALSO ao lado do par de fotos. Talvez Eric Baudelaire concorde com Erwitt. Em seu texto aqui apresentado, o artista repensa a ideia do falso na fronteira documento-ficção.

Após The dreadful details (2006), sua produção avança em direção ao vídeo e ao cinema, tendo filmes exibidos nos festivais de Locarno, Rotterdam, FID Marseille e DOC Lisboa. Em 2011, Baudelaire faz The anabasis, peça audiovisual desdobrada em livro e instalação. Para este trabalho, o artista entrevista Masao Adashi, diretor da vanguarda japonesa dos anos 1960, que deixou o cinema para integrar o Exército Vermelho japonês. Baudelaire ainda o chama para ser o narrador de The ugly one (2013) e realiza em 2017 o longa-metragem Also known as Jihadi inspirado em A.K.A serial killer (1969), principal filme de Adashi.

Nascido em 1973, Eric Baudelaire é franco-americano e tem formação em Ciências Sociais. Fez sua primeira exposição individual em 2007. No Centre Pompidou realizou APRÈS (2017), evento no qual apresentou Also known as Jihadi, curou uma exposição com trabalhos de outros artistas e promoveu um ciclo de palestras com convidados. O título, "após" em português, é uma referência temporal aos ataques do Estado Islâmico a Paris e Saint-Denis em novembro de 2015, episódio que provocou no artista a urgência em procurar uma forma e um contexto para pensar a produção de tais acontecimentos. 
Hipótese: pediria a um artista que trabalha as fronteiras do documento e da ficção, apostando nos efeitos de verdade que se produz neste encontro, para conceber uma exposição imaginária. Ele pensaria reunir obras que testemunhassem o inimaginável, habitando o lugar onde faltam as imagens. Nessa exposição que jamais aconteceria, ele traria notas sobre os poderes das imagens e sobre suas capacidades de abalar a ordem do tempo.

\section{Quioto, 13 de abril}

Essa noite, cineclube de domingo. Projeção entre amigos e discussão com um copo na mão. Essa semana, sem anunciar o programa, escolhi The war game, do Peter Watkins, no qual uma voz off fria e factual acompanhava a filmagem preto e branca de um mockumentary da BBC, descrevendo as consequências devastadoras de um bombardeamento nuclear em Kent, no Reino Unido, em 1965.

A atmosfera na sala de projeção é tensa. A extraordinária violência das estatísticas levantadas, os planos fixos intermináveis de crianças agonizando, de ossadas, de carnes queimando, congelava o sangue de nosso pequeno grupo de cinéfilos que esperava, sem dúvida, um programa dominical mais divertido. Quando o filme chegou ao final, o mal-estar era palpável, quase fisiológico. "Muito cru, muito brutal, sem nuances, sem piedade": quarenta anos após sua censura pela BBC (ainda que ela tenha encomendado o filme), a pancada de Watkins permanece intacta, a ponto de limitar um tanto do espaço crítico da discussão - é menos a um "filme" e mais à agressão visual e cognitiva a que reagimos com as tripas.

Quanto a mim, passei uma parte da projeção sentindo um constrangimento particular: um dos convidados trouxe uma amiga japonesa à projeção, e eu não sei se essa atuação de um acontecimento atômico é tolerável para alguém de uma cultura que de fato conheceu a Bomba. A discussão que seguiu foi contrária às minhas expectativas. Os rostos mais pálidos eram dos convidados franceses. A amiga japonesa parecia menos desconcertada. 


\section{Hiroshima, 21 de agosto}

Retorno a Quioto, ocasião de fazer uma parada em Hiroshima e lá visitar o Peace Memorial Museum. Documentos, artefatos e testemunhos do primeiro bombardeamento atômico apresentados em circuito cronológico, perspectivas científicas do Manhattan Project e a fabricação de "Little Boy", em que uma reprodução de escala real é apresentada numa sala.

O desafio desse memorial é complexa: dizer o horror, mas evitar os obstáculos de uma leitura da história que tenderia para o argumento (americano) de era inevitável, contornando a demonstração explícita (mas perigosa) de que a missão do Enola Gay, em 6 de agosto de 1945, era um gesto claramente político e decididamente bárbaro. A estratégia museológica do memorial é concebida ao redor de uma lógica de acumulação desordenada e polimorfa: documentos científicos e gráficos sobre a ciência do átomo, enunciações de cifras evocando a escala de destruição, maquetes e amostras arquiteturais documentando a potência da explosão e testemunhos de sobreviventes. A impossibilidade ética e historiográfica de propor uma montagem mais ordenada, selecionada e diretiva desses dados, leva então a uma estratégia do volume, da evocação e da repetição, e por consequência a uma larga abertura de interpretações, o que dá espaço para colagens, por vezes, surpreendentes.
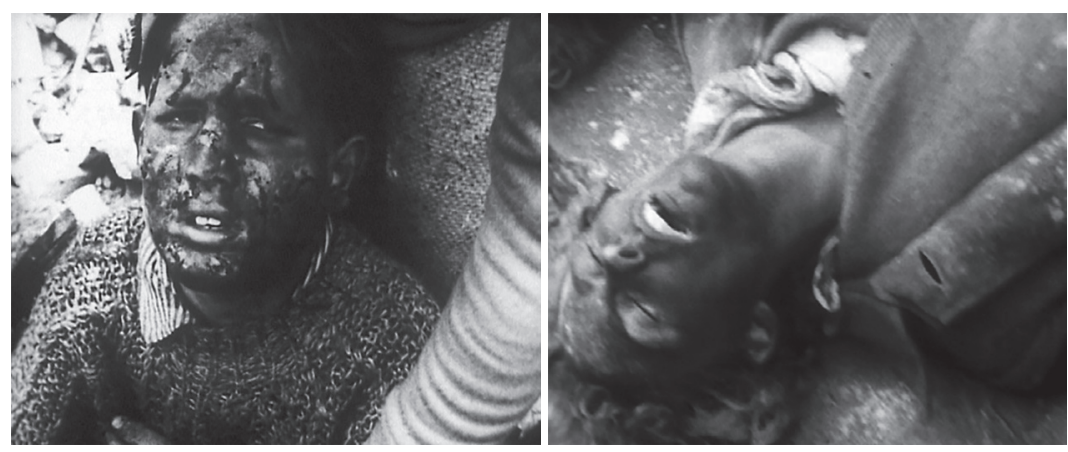

Fig. 1. Fotogramas de The war game (Peter Watkins, 1965).

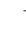

As vitrines frias e científicas sobre a física nuclear (parecidas com aquelas do Palácio da Descoberta) podem parecer deslocadas quando se está a alguns metros do pathos potente do testemunho de um sobrevivente enunciado em primeira pessoa. $\mathrm{O}$ dispositivo sugere a força de sedução da pesquisa científica (o que há de mais inebriante que a fissão nuclear onde o infinitamente pequeno dá o infinitamen- 
te potente?), um encantamento que leva numerosos cidadãos de bem,

ano 16

ก. 33

1. Mesmo se mais tarde, em uma entrevista dada em 1965 ,

o Dr. Oppenheimer evocava

o primeiro teste nuclear no deserto de Alamogordo assim:

“Sabíamos que o mundo não mais seria o mesmo. Algumas

pessoas riram, algumas pessoas choraram, a maioria ficou em silêncio. Recordeime de uma passagem das escrituras hindus, 0 Bhagavad-Gita. Vishnu está a tentar persuadir o Príncipe de que deve fazer o seu dever, e para o impressionar assume a sua forma de quatro braços e diz, 'Eu tornei-me a Morte, o destruidor de mundos.' Suponho que todos nós pensamos isso, de uma maneira ou de outra." como o Dr. Oppenheimer, a ir além da capacidade humana imediata do resultado de seus trabalhos ${ }^{1}$. A empatia pelas blusas brancas de Los Alamos não é, sem dúvida, o objeto primeiro da cenografia, mas a acumulação de dados deixa essa leitura possível, e é precisamente nesse gênero de agenciamento aberto que ganha corpo a função do memorial.

A repetição também surpreende. Na primeira sala, duas maquetes monumentais do centro de Hiroshima, uma antes e outra depois da explosão. Em uma das salas seguintes, encontra-se uma segunda maquete do depois, tomada pela mesma bola vermelha flutuando sobre o hipocentro. Dispositivo cinematográfico mais que museológico: cabe a cada um reler o mesmo objeto, como um efeito de montagem, um laço, ou uma pausa sobre a imagem de um filme.

Seguem as salas dos artefatos. Trapos de roupas queimadas; imagens de corpos irradiados disformes; o traço de uma sombra projetada sobre um muro de tijolos de um homem vaporizado pelo calor; e sem dúvida o mais macabro, essa pequena pilha de restos humanos de Noriaki Teshima, fragmentos de unhas e pedaços de pele torradas, preservadas por sua mãe para guardar um resto a que mostrar ao pai no retorno do front.

Sucessão de dados brutos, de informações científicas, relações numéricas que ultrapassam nossas faculdades de representação visual com artefatos concretos, servem de eufemismo desfigurado para uma imagem mental que cada um se fará. O que choca na visita do museu de Hiroshima é que seu desenrolar, seu funcionamento, e a sensação que ela provoca são idênticos aos de The war game, de Watkins. Ou melhor, devo dizer, o falso documentário de Watkins (1965) é articulado precisamente segundo a mesma lógica que o Hiroshima Peace Memorial Museum, inaugurado em 1955. A mesma postura na forma: a escala do horror atômico justifica (ou torna indispensável) uma exposição crua, brutal e massiva de informações e formas de visualização diversas. A mesma postura no fundo: dizer alto e forte "Hiroshima, nunca mais". A experiência do filme, em abril, e do museu, hoje, colidem no meu pensamento. Conjugar o papel do arquivo à função militante, mas com uma pequena diferença: em Hiroshima os fatos são relatados, em Watkins, eles são fabricados. Se o museu de Hiroshima se apresenta como um memorial pela paz, o objeto-filme de Watkins é um antimemorial, elaborado de maneira preventiva, na esperança de que não haja necessidade de construir um real mais tarde. 
Na massa de dados do museu de Hiroshima, cada visitante faz sua seleção visceral e parte com um fantasma a lhe assombrar. Da minha parte, dois documentos ficaram gravados na memória. $\mathrm{O}$ primeiro é um relatório americano redigido ao Ministério da Guerra, cujo comitê científico surgido do Manhattan Project preconiza uma política segundo a qual as populações civis das cidades sujeitas a um bombardeamento atômico seriam prevenidas quarenta e oito horas antes do ataque, dando assim o tempo de evacuação. A argumentação deste memorandum é mais utilitária do que humanitária.

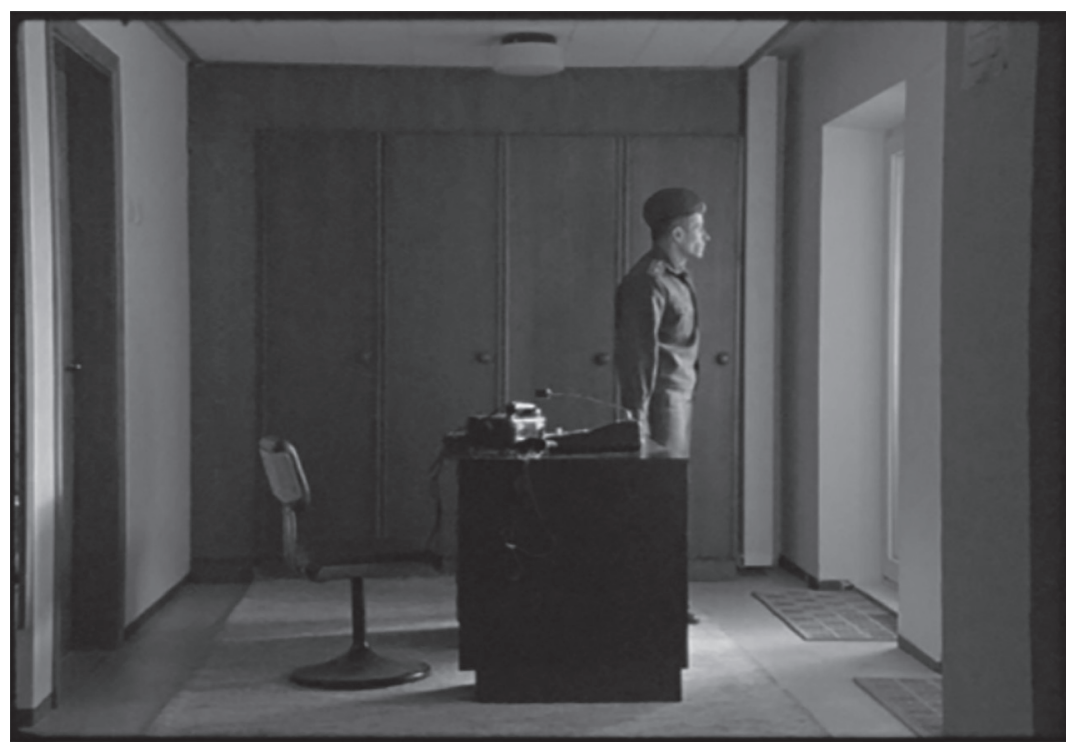

Serve para demonstrar que todos os objetivos estratégicos da bomba podem ser alcançados sem as consequências negativas, como seria um massacre de civis em grande escala na ocupação do Japão pós-guerra, e na imagem dos Estados Unidos perante o mundo. A proposição do "aviso" foi debatida, mas em última instância não foi incorporada.

O segundo documento evoca o destino da cidade de Kokura, alvo previsto do segundo bombardeamento atômico, em 9 de agosto. Trata-se de uma sequência filmada a partir de um segundo avião, mostrando o itinerário do bombardeiro Bockscar, seus três círculos sobre Kokura à procura de um buraco no céu nublado imprevisto, tornando impossível a identificação visual do objetivo, e finalmente seu desvio para o alvo secundário: Nagasaki.
Fig. 2. Fotograma de The dud effect (Deimantas Narkevicius, 2008 - cortesia do artista e gb agency, Paris). 

documento abre espaço, assim, para uma ficção dolorosamente próxima, em que os argumentos razoáveis de pessoas civilizadas teriam salvo centenas de milhares de vidas. $\mathrm{O}$ segundo documento é uma ventana sobre o estranho destino de uma cidade salva do inferno por algumas nuvens. Na linguagem factual e precisa das comunicações militares, no cabeçalho do Secretário da Guerra e na sequência do filme em 16mm de um avião prateado navegando no belo céu azul, o horror do real é posto lado a lado a outra História possível, do imaginário deste que foi evitado, ou poderia ter sido: é o espaço fictício do futuro do pretérito composto, do teria sido. O filme de Watkins é o dispositivo em espelho: usurpando o formato de um documentário da BBC, ele apresenta o

2. Esta é a definição gramatical do francês. Em português, em geral, é traduzido, como na presente versão, para o futuro do presente. (N.T.) documento aterrador do futuro anterior ${ }^{2}$, do terá sido.

\section{Paris, semana do 13 de outubro}

Notas de reflexão para o comissariado da exposição "Factographies": Se o século XX é aquele da imagem, suas horas mais sombrias são demarcadas pelas lacunas de representação. Há poucas fotografias no museu de Hiroshima porque não há imagem "suficiente" para dizer Hiroshima. Há o ícone da nuvem-champignon, mas este é mais um símbolo gráfico genérico do que uma fotografia (quem pode distinguir o champignon de Hiroshima daquele de Alamogordo ou de Bikini?). Nada de imagens das valas comuns, de cadáveres a perder de vista, apenas imagens das ruínas do depois - o vazio arquitetural como substituto visual para a pulverização dos corpos. Os traços humanos foram reconstituídos através de um diorama pelo museu, clareado por uma luz escarlate, representando duas crianças titubeantes pelos escombros: pedaços de carne queimada sobre os rostos e mãos de manequins. Por que essa mise-en-scène mórbida e teatral? Sem dúvida para substituir as imagens que faltam - aquelas que talvez tenham desaparecido com a ocupação americana, aquelas que não existiram porque não existiram pessoas para fazê-las, ou aquelas que faltam porque a Bomba não deixou mais do que restos humanos a se fotografar. Não há então, não pôde haver, imagens do acontecimento atômico. E se houvessem, elas seriam suficientes?

Essa questão da representabilidade do inimaginável liga $\mathrm{Hi}$ roshima a Auschwitz. Porque apesar do sistemático narcisismo pornográfico da documentação nazi dos campos, também não há imagens 
das câmaras de gás, afora os quatro fragmentos de filmes do Sonderkommando cuja publicação deu lugar à polêmica e ao belo texto de George Didi-Huberman, Images malgré tout. A interdição absoluta de se fotografar nas câmaras de gás (mesmo para os SS) não impediu alguns detentos anônimos de arrancar do inferno de Auschwitz essas quatros imagens borradas, únicos documentos fotográficos conhecidos representando o funcionamento do dispositivo principal dos campos de extermínio. Esse valor simbólico de imagens únicas do sistema de destruição do povo judeu é, em suma, o epicentro do debate sobre a capacidade da imagem de dizer o indizivel da Shoah. Imagens inadequadas, pois elas mostram muito pouco frente à amplidão do Holocausto. Imagens inexatas, pois imprecisas. Imagens fragmentárias que não souberam figurar mais que uma verdade insignificante frente à escala impensável de Auschwitz. Daí, se não se pode ter uma imagem toda, única e integral da Shoah, não se deveria destituir todas as imagens? Gérard Wajcman argumenta assim a invisibilidade do genocídio ao lado de Claude Lanzmann, que irá dizer: "Se eu tivesse encontrado um filme existente [...] rodado por um SS mostrando como três mil judeus, homens, mulheres, crianças, morreram juntos, asfixiados em uma câmara de gás do crematório II de Auschwitz, se eu tivesse encontrado isso, não somente não o teria mostrado, como o teria destruído. Eu não sou capaz de dizer o porquê. É natural”’3.

Frente a Lanzmann, para quem nenhuma imagem é capaz de dizer a história, Jean-Luc Godard, em História(s) do cinema, trabalha uma montagem de imagens existentes para demonstrar que agora todas as imagens não falam senão disso, concedendo-lhes assim um potencial redentor já que "mesmo riscado de morte/um simples retângulo/de trinta e cinco milímetros/salva a honra/de todo o real" ${ }^{4}$. Nesta polaridade polêmica, a oposição entre iconoclastas e iconofílicos, interessa-me sobretudo as vias que se abrem aos artistas frente ao diagnóstico partilhado sobre a pobreza das imagens: ao modo de Lanzmann elas são abandonadas para se dedicar à palavra e ao testemunho; ao de Godard, revistas, relidas e colididas para serem reinventadas à luz da História. A esta dialética, é preciso adicionar uma terceira via, aquela de Watkins: frente à natureza lacunar das imagens, fabriquemos imagens! Fabriquemos um excesso de imagens, uma barragem de imagens, uma sobredose de imagens. Mais que isso, pelo dispositivo do falso documentário, elevemos essas imagens ao estatuto de símile-documento.

\section{Eric Baudelaire}

Potências do falso.

3. Citado em DIDIHUBERMAN, Georges. Images malgré tout. Paris: Les

Éditions de Minuit, p. 122.

4. GODARD, Jean-Luc. Histoire(s) du cinema, I. Paris, Gallimard-Gaumont, 1998, p. 86. 
Evidentemente, no terreno delicado das grandes tragédias humanas, a fabricação de imagens é uma empresa arriscada... O obstáculo pode estar na mediocridade cinematográfica e na platitude estabelecida. No simulacro de Auschwitz de Steven Spielberg, o problema está na inserção, dentro de uma ficção puramente clássica, do preto e branco em falsas imagens de arquivo, para realçar uma empresa espetacular. Roberto Benigni, por sua vez, opta por uma mise-en-scène quase burlesca da tragédia - um pouco leve para o gosto de alguns, seu filme se liga no entanto à estratégia de Imre Kertész (que aliás o defendeu), e do essencial do teatro israelita sobre a questão, tratando-as menos como falsas imagens do que como pura teatralização enquanto única via possível para evocar a Shoah.

A questão é então saber onde situar a grande obra factográfica de Watkins. Sua tarefa cinematográfica (tenho quase vontade de falar em missão de tanto que seu método de trabalho recupera o sacerdócio), compreende ao menos dois objetivos: revisualizar episódios históricos ameaçados por um revisionismo dominante para se reapropriar (Culloden, La commune), e inventar cenários assustadores em seu realismo (The war game, Punishment park) por urgência política. Os dois gêneros se religam em suas vontades profiláticas. Os painéis históricos também são filmados com um dispositivo de mise-en-abîme midiático, um anacronismo que permite desenvolver um olhar crítico sobre as questões da escritura da História pela comunicação de massa, e de sublinhar a contemporaneidade das problemáticas políticas dos acontecimentos datando uma pluralidade de séculos. Mas o engajamento é mais urgente ainda em filmes de ficção pura: The war game deveria ter circulado apenas três anos após a crise dos mísseis de Cuba, quando a humanidade de fato passou por um triz do Armagedom, e os excessos de Punishment park não parecem mais tão fictícios na era de Guantánamo, dos afogamentos simulados e dos extraordinary renditions da CIA.

Para Maurice Blanchot, "há um limite onde o exercício de uma arte, qualquer que ela seja, torna-se um insulto à desgraça”. Watkins aborda o problema em sentido inverso: insultar a desgraça seria justamente não exercer a arte a fim de repelir seus limites. Falar do "indizível" relativo ao horror genocida não nos leva ao que Giorgio Agamben descreve como uma "adoração mística" que contém o risco de tender para o silêncio ${ }^{5}$ ? Para Watkins este silêncio é que seria intolerável, então ele Rivages, 1999. 
mental que emana das palavras e dados históricos, ele fabrica imagens. Ele confia na sua eficácia, sob a condição de sair do registro neutralizante da imagem-clichê banalizada onde Spielberg, ou Benigni, se enganam. Isso se dá por dois meios: seu volume (repetição, acúmulo e caráter explícito) e sua proximidade (ele nos recolhe a nosso mundo, a Kent, e não ao Japão distante e exótico). O imperativo político consiste em trazer violentamente o assunto para nossas salas: Bring the war home como logo mais defenderia Martha Rosler, atualizando o método de choque de Orson Welles com sua radiotransmissão de Guerra dos Mundos.

A questão da fabricação, da falsificação ou da descontextualização de documentos leva a dois pontos essenciais: o que faz imagem e o que uma imagem faz. Para Watkins, a imagem tem uma função alarmista (no sentido positivo do termo), ele então elabora o espaço fictício do documento e finca sua função preventiva. Nesse sentido, suas imagens aparentam-se às imagens mentais que emergem dos documentos de $\mathrm{Hi}$ roshima, àquelas que me fizeram vislumbrar o que teria sido o fim da guerra sem as centenas de milhares de vítimas civis dos bombardeamentos atômicos, ou visualizar o acaso dilacerante que fez Kokura poupada e Nagasaki arrasada. E talvez essa aproximação, justamente, explique a reação mais estável dessa amiga japonesa no cineclube: ela já havia visitado este lugar, no sentido figurado. Mais familiarizada com o material, ela estava mais apta que nós a apreender o projeto de Watkins em sua essência, a saber, o antimemorial de um cataclisma iminente mas evitável.

Justapor uma ficção que tende para o documento, e documentos que abrem a via para uma ficção. Fazê-los dialogar em um mesmo espaço expositivo.

George Didi-Huberman diz da importância das imagens apesar de tudo, sublinhando que "cada produção testemunhal, em cada ato de memória, os dois - linguagem e imagem - são absolutamente solidários, não cessando de trocar suas lacunas recíprocas: uma imagem vai onde a palavra parece falhar, uma palavra, com frequência, vai onde parece falhar a imaginação" .

Da mesma maneira, "Factographies" propõe uma reflexão sobre as práticas artísticas tornando absolutamente solidários documento e ficção, cada um atenuando a insuficiência do outro. E já que a dialética Watkins/Museu de Hiroshima, produção testemunhal do 
ARS teria/terá sido, se coloca em torno da ideia essencial de antimemorial, ano 16 a introdução de uma nova peça à exposição se impõe: "Factographies"

n. 33 deve incluir a documentação do projeto COMMEMOR (Comissão mista de troca de monumentos aos mortos), 1970, onde Robert Filliou orquestra, com a leveza potente que o torna aqui indispensável, uma troca fictícia de monumentos aos mortos entre cidades da Holanda, Alemanha e Bélgica no lugar de guerras verdadeiras. COMMEMOR como resposta escultural ao gesto cinematográfico de Watkins.

\section{Bruxelas, 18 de outubro}

Ao acaso de uma volta, visito a galeria Jan Mot onde acontece o vernissage da exposição de Deimantas Narkevicius com a projeção de seu filme The dud effect. Acaso milimétrico: estou a caminho de fechar a seleção de obras para "Factographies" e dou de cara com esse filme que é em parte inspirado, ou digamos, realizado em conexão à The war game, de Watkins. Narkevicius põe em cena o antípoda dos acontecimentos fictícios de Kent em 1965: o lançamento de mísseis nucleares R-14 a partir de uma base soviética na Lituânia nos anos sessenta.

The dud effect é o contraponto de The war game do ponto de vista narrativo (mise-en-scène do lançamento no lugar do impacto), mas também estilístico: tudo é feito para dar à ação um caráter ordinário, burocrático, ordenado. Nada de emoção nos planos, apenas a descrição clínica da rotina administrativa. Não é uma questão a decisão do lançamento dos mísseis (não se explicitam questões morais), e seu impacto é apenas sugerido nas cavidades. A maior parte do filme mostra um oficial anônimo dando ordens de natureza técnica pelo telefone a interlocutores também anônimos ("posto 101", "posto 505”). Documentário (por se basear em procedimentos verdadeiros) mais que cinematográfico (nada de botão vermelho, de controles eletrônicos, apenas uma voz no telefone e um homem impassível). Na hora do lançamento, o rosto do oficial é simplesmente superexposto pela luz dos reatores extracampo. A sequência dos acontecimentos é sugerida em planos da natureza local, um som de vento violento, e depois uma série de planos fixos atuais das instalações nucleares soviéticas em estado de degradação avançado (silos vazios, hangares sucumbidos). Estamos vendo um mundo pós-apocalíptico ou simplesmente ruínas do tempo, marcas que asseguram o fim do império soviético? Se se trata da segunda hipótese, porque não ficamos confortados com essas imagens de um passado que nunca aconteceu? 
Ao teria sido do Museu de Hiroshima, ao terá sido de Watkins, e ao futuro do pretérito de Filliou, é necessário adicionar o não foi de Narkevicius. Nessa conjugação de obras, entre outras constantes em ligação com seu valor "memorial", está essencialmente posta a questão do tempo e da verdade, ou ainda, a maneira como o tempo coloca em crise a noção de verdade.
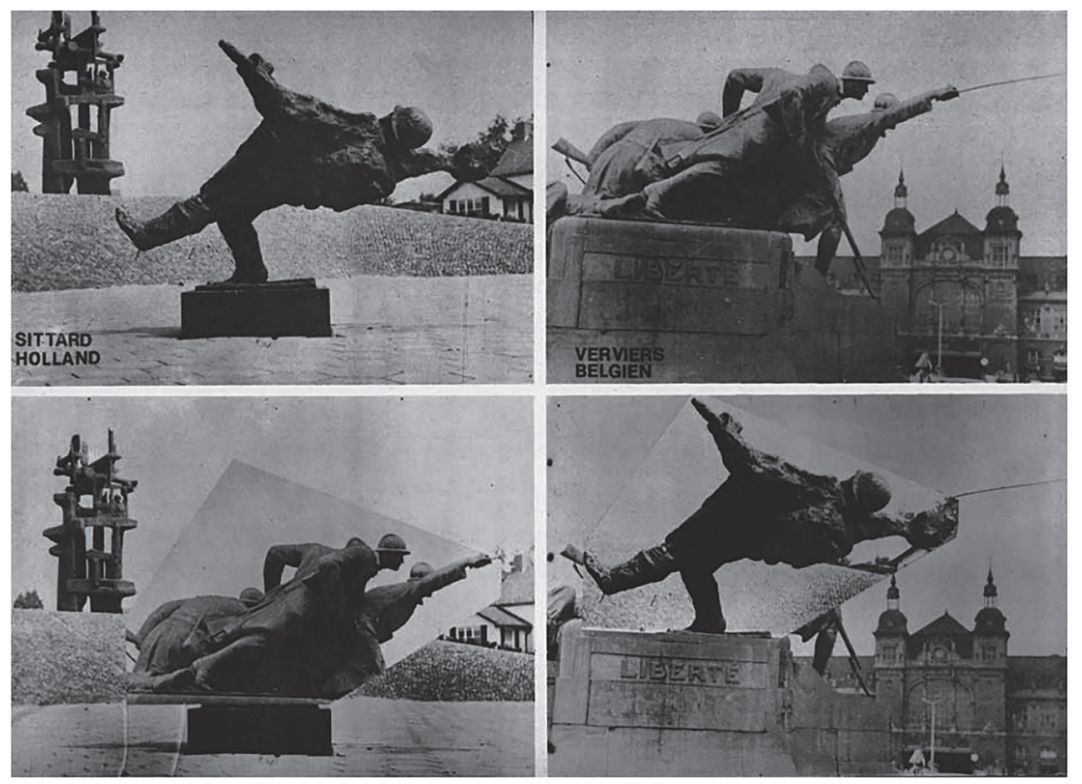

Essas diferentes narrações dos fatos ilustram o paradoxo dos "futuros contingentes”, problema filosófico revisitado desde a Antiguidade e resumido assim por Gilles Deleuze: "Se é verdade que uma batalha naval pode acontecer amanhã, como evitar uma das duas consequências seguintes: ou o impossível procede do possível (já que, se a batalha acontece, não é mais possível que ela não aconteça), ou o passado não é necessariamente verdadeiro (já que ela não podia acontecer)”7. Leibniz traz uma solução muito apropriada deste paradoxo para nós: a batalha naval (como o bombardeamento atômico) pode acontecer ou não, mas não no mesmo mundo, ela acontece em dois mundos que não são "compossíveis" entre eles. Inventando a noção de "incompossibilidade" ele resolve o paradoxo oferecendo uma pausa à crise de verdade, já que é o incompossível (e não o impossível) que procede do possível. "O passado pode ser verdadeiro sem ser necessariamente verdadeiro". E aqui Deleuze evoca a resposta de Borges à Leibniz (e nós invocamos

\section{Eric Baudelaire}

Potências do falso.

Fig. 3. COMMEMOR (Robert Filliou, 1970). Troca fictícia de monumentos aos mortos entre Sittard (Holanda) e Verniers (Bélgica).

7. DELEUZE, Gilles. Cinéma 2, L'image-temps. Paris: Les Éditions de Minuit, p. 170. 
ARS Watkins e Narkevicius da mesma maneira): "a linha reta como força do ano 16 tempo, como labirinto do tempo, é também a linha que se bifurca e não

n. 33 para de se bifurcar, passando por presentes incompossiveis, retomando passados não-necessariamente verdadeiros" . $^{\text {. }}$

Os documentos e obras de "Factographies" dialogam nessa si8. Ibidem, p. 171. multaneidade. A exposição se constrói, de alguma maneira, ao redor dessa ideia deleuziana das "potências do falso", que destronam e se substituem à forma da verdade - potência artista, criadora, onde a narração abandona o estatuto do verídico para se falsificar, e isso não em nome de uma simples subjetividade do autor ("cada um com sua verdade"), mas por uma real necessidade para a qual não haveria outra saída senão a de preencher o espaço entre estória e história.

Uma versão deste texto foi publicada no número 2010 da revista Trouble, como catálogo de uma exposição fictícia intitulada "Factographies".

\section{Bibliografia}

AGAMBEN, G. Ce qui reste d'Auschwitz, Paris: Rivages, 1999.

DELEUZE, G. Cinema 2, L’image-temps, Paris: Les Éditions de Minuit, 1985.

DIDI-HUBERMAN, G. Images malgré tout, Paris: Les Éditions de Minuit, 2003.

GODARD, J.G. Histoire(s) du cinéma, Paris: Gallimard-Gaumont, 1998.

Eric Baudelaire é artista plástico e cineasta, formado em ciências políticas pela Brown University em Rhode Island, Estados Unidos.

Lucas Eskinazi é mestrando em Poéticas Visuais na Escola de Comunicações e Artes da Universidade de São Paulo [PPGAV-USP].

Artigo recebido em 10 de janeiro de 2018 e aceito em 08 de julho de 2018.
Nina Guedes é graduada em Artes Visuais pela École Nationale Supérieure d'Arts Villa Arson. 